\title{
Translation Model and Dissemination of Contemporary Chinese Ethnic Literal Works Into the World: An Analysis on English Translation of The Last Quarter of the Moon by American Translator Bruce Humes*
}

\author{
Yuxuan $\mathrm{He}$ \\ Inner Mongolia University, Hohhot, China \\ Jinyu Liu ${ }^{1}$ \\ Inner Mongolia University, Hohhot, China \\ Jianhua Wang \\ Foreign Languages College, Inner Mongolia University, China
}

\begin{abstract}
This study aims to investigate the English translation model and strategy of contemporary Chinese literary masterpiece The Last Quarter of the Moon (2005), taking Nord's translation-oriented text analysis as a theoretical tool. The paper is composed of the translation commission, the role of ST analysis and hierarchy of translation problems, including the basic information about the writer, the original book, the English translation and the translator. Comparison of the ST with its English TT in terms of aspects of language, culture and communication will be discussed. Specifically, this paper explores the translation strategies that the translator has adopted at the linguistic level in translating Evenki proper nouns and idiomatic expressions, the dialogue of main characters, figures of speech, then explores the translation strategies of rendering Evenki folk customs, sacrifices, totemism and ceremonies from the aspect of ethnic culture. The study shows much importance is attached to the linguistic features and cultural connotations of the original work both at the linguistic and cultural level. The translation accurately and faithfully conveys the essence of the novel, successfully attracts the attention of western readers and promotes the spread of Evenki culture. The translation also makes a comprehensive analysis of the surface and deep meanings of the original text, effectively conveys the theme of the original work, and further promotes the "going out" of ethnic literature to the world.
\end{abstract}

Index Terms-The Last quarter of the Moon, Nord's text analysis, ethnic literature, comparative analysis

\section{INTRODUCTION}

Ethnic literature is an important embodiment of national history and culture. It plays a unique role in the overseas dissemination of Chinese ethnic culture. Chi Zijian's book The Last Quarter of the Moon (2005), published by the People's Literature Publishing House, is the first novel describing the survival status and hundreds of history of the nomadic Evenki people in the northeast China. The work tells the Evenki people's tenacious perseverance and cultural changes, and expresses the pursuit of the ideal human spirit such as their respect for life, reverence of nature and adherence to their faith. Due to her exquisite skill in style, artistic conception, ideology and artistry, she won the 7th Mao Dun Literature Award in 2008. The English version, The Last Quarter of the Moon (2013) was translated by Bruce Humes, a young Sinologist, later on translated into Dutch, French, Japanese, Korean and Spanish.

The novel itself contains a postscript and four parts, which are respectively titled "Dawn" "Mid-Day" "Dusk" and "The Last Quarter of the Moon”. The narrator is a 90-year-old woman, a wife of the last chief, recalled her whole life by means of telling a story. Hundreds of years of history of Evenki people were vividly depicted through exquisite language. The story starts in the narrator's childhood and ends in her last years of life. The novel reveals the destruction of the traditional

\footnotetext{
* This paper marks a stage in a research that was made possible by the funding supported by National Social Science Program (grant \#20BYY027) ; China national Committee for Translation and Interpreting Education (MTIJZW201816), Education Bureau of Inner Mongolia Autonomous Region Youth Elite Program (grant \#NJYT-20-A01) and Postgraduates Pedagogical Reform and Practice (grant \#YJG20181012613),Inner Mongolia University Course Design Program "Translation Theories" and "A General Introduction to Western Translation Theories" (grant \# NGHWZ201702, 2018, 2019).

${ }^{1}$ Corresponding author
} 
way of life and the environmental pollution during the process of modernization, which illustrated the value of this study. Through the novel, the writer consciously emphasizes the "natural attributes" of human beings, thereby embodying the creative concept that man and nature can unite as one. Meanwhile, the writer tried to express the embarrassment, sorrow and helplessness encountered in the course of human civilization through the description of the vast mountain forest and the safari tribe that lives in the forest, which is the main purpose. The time of the story lasts a century, while the narrative time of the novel is only a short day. A day of narrative time tells the story of a century-long demise of a nomadic people from prosperity to its decline.

\section{Humes Bruce and His Decision-Making Process in Translating}

Humes Bruce, the translator, has been devoted to his translation career for several years and at the very beginning he specialized in translating Chinese-language fictions, one of which is Wei Hui's Shanghai Baby. Bruce was commissioned and the translation was published in 2001 and gained much popularity. Later, he has centered on some fictions by or about China's ethnic minority because he wonders how people view those minority groups, how Chinese writers portray the lives of those people and how they manage to deal with the evitable trend when coming into a more frequent contact with the outside world. Humes is curious about the languages of ethnic groups which even have no written script or at the verge of extinction. The minorities can tell their tales in form of their own languages but Bruce wants to explore how the Han writer decoded and perceived their language in his literary work. All these topics have motivated Bruce to move on to translating China's ethnic literature. Bruce translated the story about reindeer-herding Evenki named The Last Quarter of the Moon at first, which is the story about reindeer-herding Evenki. His desire to explore how the majority Han viewed the minority groups inspired him to enter the unique life of Evenki.

This is a big achievement in his translation career and opens a window for westerners, which contributes to the "going out" of Chinese culture. After The Last Quarter of the Moon was published, Bruce continued to explore how non-Han writers use their own languages to tell their own stories. He translated Confessions of a Jade Lord about the Uyghur in Xinjiang. The non-Han writer of Confessions of a Jade Lord, Alat Asem won 11th Junma Literary Prize and tried to takes the readers into the colorful world of Xinjiang's jade traders. Asia-Pacific Journal has published an excerpt that Bruce translated. The text is from Guo Xuebo's contemporary work, Mongoliya, which is a semi-autobiographical and is set in 21 st century in Inner Mongolia. The writer is a Mongol and he grew up speaking the language of his people.

Bruce also translated the Manchu writer Ye Guangcen's short novel Back Quarters at Number 7 and the translation was published in the magazine Streetlight on June 1st, 2014. He translated the short story Green Tara by a Tibetan writer was published in Streetlight in 2016. It is worth mentioning that magazine Street Light is also considered as the path of Chinese literature to the world and provides an important platform for English translation and overseas communication. It has built a bridge between Chinese writers and English readers. Hu (2010, p. 11) holds that for those sinologists who take advantage of their language and cultural background, they are both researchers and critics. They are quite influential in spreading Chinese culture and promoting the development of Chinese literature in their academic field or through western mass media.

\section{THEORETICAL FRAMEWORK}

Nord, as a major functionalist, stresses that while "functionality is the most important criterion for a translation, this does not allow the translator absolute license" (2005, pp. 31-32). The nature of this relationship between ST and TT is determined by the purpose or skopos. Therefore, form her point of view, for the translator, it is necessary to know why a ST is to be translated and what the function of the TT will be. Nord continues to explain that by explaining that 'the target-text purpose should be compatible with the original author's intentions', while acknowledging that it is not always possible to be sure of those intentions. For her, loyalty plays the important role in that it 'limits the range of justifiable target-text functions for one particular source text and raises the need for a negotiation of the translation assignment between translators and their clients' (Nord, 1997, p. 126).

Christiane Nord provides a more detailed functional model incorporating elements of text analysis, which examines text organization at or above sentence level. Nord first makes a distinction between two basic types of translation product and process, which are documentary translation and instrumental translation. Documentary translation "serves as a document of a source culture communication between the author and the ST recipient" (Nord, 2005, p. 80).

\section{An Analysis of Translation Strategy and Procedures of The LaSt Quarter of the Moon}

The importance of the translation commission is illustrated and the ST analysis is carried out including the intended life experiences of the translator, his academic interest and his translation career to make sure the qualification of the translator. In this section, translation strategies that Humes adopted will be elaborated through a close analysis of the English version and the Chinese original one from linguistic, cultural and communicative aspects, including the subject matter, the content, presuppositions, micro structure defined as text composition and other aspects such as lexis, sentence structure. Through comparison, how the features and functions of the ST are reflected and fulfilled in the target text will be elaborated. Using Nord's text analysis model above, it is clear that the kind of translation involved here is document translation, this chapter will focus on how the translator deal with the features of ST and how the translation reflects the 
function of ST.

\section{A. Reproduction of Linguistic Features in Translation}

Language is the carrier of culture. The language of minority groups has strong ethnic characteristics. For Nord, it is necessary to know where the ST and TT may diverge. From the linguistic dimension, the adaption of the translator is reflected in the appropriate selection of words, sentences and discourse. It is the translator's responsibility to make the translation accurate, which reflects Nord's definition of loyalty. Firstly, as to the linguistic features of the novel You'An, it is first-person narrated which makes it easier for the readers to feel the happiness and sorrow of Evenki people. The plot is more believable by using the first person "I".

\section{B. Reproduction of Proper Names Specific to Evenki}

Terms specific to Evenki are mainly divided into three types in the original text, which are the names of characters, place names and terms specific to Evenki culture. Evenki is an endangered language, which Western readers are not familiar with. In translating the names of Evenki people and place names, the translator Bruce Humes adopted the pronunciation of Evenki language rather than use Chinese Pinyin. When Humes launched an article Evenki Place Names behind the Hànzì, on his blog Ethnic ChinaLit, and told that he consulted the expert of Evenki language for the exact pronunciation and used the international alphabet to spell them. He also proved that all the names of river and mountain do exist.

In the target text, he transliterated 列斯元科山 into Listvyanka Mountain. He transliterated Evenki name 林克 into Linke, but translated those Russian names by adopting Russian pronunciation like 娜杰什卡 into Nadezhda. The rest of characters names are all translated in this way, which retains the exotic colors for the target readers to arouse their interest.

Bruce wonders how many names of rivers and mountains and cities can be traced in China and how the origin of the memories can be hided in the meanings of these place names. To preserve the exotics of ethnic literature, the translator used Evenki pronunciation to transliterate these proper names. In the process, he searched some Evenki-related reference books written and published in China and consulted the remarkable Evenki scholar Dr. Chao Ke. He used International Phonetic Alphabet to mark each word, which preserves the original Evenki features.

\section{Reproduction of Figures of Speech of the Original Text}

One of the distinctive features in The Last Quarter of the Moon is the frequent use of figures of speech, indicating the ethnic color of Evenki people and their affection for plants, animals, rivers and mountains. "The writer consciously compared human beings with plants and animals, showing the idea that man and nature are united as one" (Liu, 2012, p. 61). The figurative language can express special meanings different from their ordinary meanings by using some words. In translation, Humes nearly preserved all the metaphors or similes and reproduced the style of the original text.

Example 1

ST: 那暗红色的肉条，就像被风吹落的红百合的花瓣。（Chi, 2010, p.43）

TT: Those crimson meat-strips looked like red lily petals blown to the ground by the wind. (Humes, 2013, p. 41 )

Example 2:

ST: 野兔的内脏就像鲜红的花朵一样开在林地上, 冒着丝丝热气。(Chi, 2010, p. 23)

TT: The hare's innards spilled on the forest floor like a fresh red blossom emitting sizzling plumes of steam. (Humes, 2013, p. 22)

Example 3:

ST: 她从来不正眼看杰芙琳娜，吩咐她做事的时候，眼睛永远看着别处，

好像杰芙琳娜是一朵有毒的花。（Chi, 2010, p. 160)

TT: Maria's eyes avoided her gaze, as if Zefirina were a poisonous flower. (Humes, 2013, p. 161)

Example 4:

ST: 不让她沾冷水, 不让她嬖柴, 不让她给驯鹿喂盐, 怕哪只驯鹿要是突然淘气了,会踢了她的肚子, 打落他最想得到的花朵。（Chi, 2010, p. 135）

TT: He wouldn't let her touch cola water, chop firewood, or feed salt to the reindeer out of fear one might naughty and kick her belly, causing his cherished blossom to fall (Humes, 2013, p. 159).

These four examples are concerned about the image "flower". The blossom, petals, all represent something beautiful but delicate. In Evenki's life, everything about nature can sense people's feelings. They believe that everything has a soul so the writer injected her deep love for the nature including the plants so she frequently.

\section{Transformation of Chinese Idiomatic Expressions}

There are only a few examples concerning the use of Chinese slang in the original fiction, the typical two of which are listed as follows.

Example 5:

ST: 如果被日本人知道, 恐怕没什么好果子吃。（Chi, 2010, p. 104）

TT: If the Japanese find out, who knows what's in store. (Humes, 2013, p. 104)

Example 6:

ST: 我们藏起来的东西, 他去寻找, 跟登天一样地难。（Chi, 2010, p. 145） 
TT: If we had concealed something, searching for it would be as difficult as climbing to the Heavens. (Humes, 2013, p. 145)

In the above two cases, "恐怕没什么好果子吃" and "跟登天一样地难" are both Chinese-specific expressions - concise but rich in connotation. The former comes from Huainanzi, implying that there are no good endings or results. For Chinese readers, they will naturally be familiar with the meaning of "果子", so there are no obstacles to understanding; but for Western readers, they do not understand the meaning behind “好果子吃” which will cause some confusion. Here, the translator chose to use free translation to explain the meaning implied in the original text. At the same time, he preserved the stylistic features of the original text by using the form of slang to reflect character's personalities, which is quite accurate and easy to understand.

The latter is “跟登天一样地难”. The expression in the source text indicates the fact that the Japanese cannot find hunting products from the Evenki camps, which is linked to Chinese slang and quite vivid and concise. In order to convey the connotation more accurately, the translation has to consider which word can be used to correspond to "天" in the source text. In Chinese, the word "天" has rich meanings and can be translated as "sky" "heaven" "God" or "Spirit" in different contexts. In the last part, Bruce translated “天” into "Spirits" but here used heavens, which means sky. The expression 'as difficult as' is used to explain the degree difficulty. The translator fully understood the meaning of the slang and literally translated it, which preserved the exotic elements about Chinese culture.

\section{E. Translation of the Ecological Issues}

Apart from the Evenki culture and reflected in Evenki people's daily life, this work is also characterized by ecological theme. For one thing, the Evenki Spirit is characterized by the self-sacrifice spirit of Shamanism. For another, the work depicts Evenki peoples' strong belief that nature and human beings should be harmonious.

Example 7:

$\mathrm{ST}$ : 我问她这是为什么, 妮浩说, 天要那个孩子去, 我把他留下来了, 我的孩子就要顶替他去那里。那你可 以不去救他啊! 玛利亚哭着说。妮浩凄凉地说, 我是萨满, 怎么能见死不救呢? (Chi, 2010, p. 143)

TT: 'Why?' I asked.

'The Heavens summoned that child. But I kept him here on the earth, so my child had to go in its place.'

'You could have refused to save the sick child!' sobbed Maria.

'I'm a Shaman,' said Nihau forlornly. 'How can I see someone in death's clutches and not save him?' (Humes, 2013, p. 142)

This example shows that Nihau the Shaman chose to save a child in danger even though she knew she will lost a child at the same time. In this novel, the Shaman is granted the extraordinary power that she can pass the thinking of the "God" to Evenki people's thought. The descriptions and dialogues about Shaman all indicate the self-sacrifice spirit. In translation, the translator chose to retain descriptions indicating the strong characteristics of Evenki people, including the courage, kindness and the self-sacrifice spirit have been accepted by the translator. Meanwhile, he devoted himself to promoting such kind of spirit based on his translation, which also marks translator's centeredness affecting his translation process and his adaption and selection in terms of other factors in translation.

When Nihau was a Shaman, she prayed for the heavy rain to put out the fire at the expense of her own life. The writer Chi Zijian recorded the Shaman culture of Evenki tribe with strong feelings, and praised shaman's sacrifice spirit and noble personality. However, the shamanic culture is endangered. Nihau might be the last shaman of the Evenki people, because most of them have settled in Busu since then. The new shaman did not appear. Perhaps the Evenki folk culture and shamanic culture can only exist in historical documents, and the Evenki people's ethnic cultural heritage may gradually disappear with time passing by - this is always the hidden pain of the narrator "I".

Shamanism, including mysterious spirit dance, selfless spirit and responsibilities, together with the great worry and pain about gradual disappearance of the ethnic cultural heritage has made up the main idea of the original book. The translator still tried to make the translation accurate and avoid the missing of such a respectable spirit because his evaluation and full understanding about the features and functions of ST always motivates him to do so.

Example 8:

ST:

我很想对他说, 我们和我们的驯鹿 '”, 从来都是亲吻着森林的。我们与数以万计的伐木人比起来, 就是轻轻 掠过水面的几只蜻蜓。如果森林之河遭到了污染, 怎么可能是几只蜻蜓掠过的缘故呢? (Chi, 2010, p. 259)

TT: I really wanted to tell him that our reindeer have always kissed the forest. Compared to the loggers who number in tens of thousands, we and our animals are just a handful of dragonflies skimming the water's surface. If the river that is this forest has been polluted, how could it be due to the passage of a few dragonflies? (Humes, 2013, p. 259)

In this example, Chi Zijian stressed the main idea of the novel in the last part through the words of the narrator. Evenki people and their reindeers are not the cause of environment pollution. Instead, it is the loggers who cut down the trees and destroy the forests. The word "kiss" indicates the harmony between Evenki people and nature as well as their strong feelings towards the reindeer. They live in the forest and they love the forest. They are the victim of the environmental pollution. Due to the modernization, their traditional Evenki culture was destroyed and it was difficult for them to come back to their initial life, which has made up the main idea of chi Zijian.

In the translation, the translator faithfully expressed the idea of the original fiction. He preserved both the content and the form of the source text. These reasons have contributed to the spread of Evenki culture and made the work profound 
by highlighting the harmony between man and nature. There are another two examples that can also indicate the main idea of the writer.

\section{CONCLUSION}

In the English translation, the characters and nature are perfectly combined. Humans are the manifestation of nature, and nature owns human beings' form of life. The relationship between nature and humans is also the way of establishing the law of human life. Chi Zijian calls for human's respect for nature, expressing the distress and anxiety of human beings' existence, showing the meaning of life in the natural realm.

The writer tried to show the close relationship with nature through narrator's narration and use a large number of descriptions to indicate that the plants, mountains and rivers and other things related to nature greatly affect the destiny of almost every character. However, she also pointed out that the beauty of nature was disappearing, and people's ignorance has made nature worse. People often treat the surroundings indifferently due to their own selfishness, not only destroying their living environment, but also destroying the meaning of life itself. Chi Zijian established a profound theme about the relationship between man and nature and the destruction of traditional ethnic culture in the process of modernization. She did not write nature simply for describing nature, nor did she merely use nature as the background for the story. Instead, in the novel, nature affects the physical, moral and spiritual aspects of Humans. The work reveals the connection between man and the earth also emphasizes the harmonious coexistence and interdependence of human beings and nature, which is the main theme of the work.

The research holds that most Evenki proper nouns are transliterated, which is close to the pronunciation of Evenki language; Idiomatic expressions are translated in a flexible way through direct translation and free translation, basically retaining the form of the original idioms; the quotation of the dialogue tends to be converted according to the context so as to make the characters prominent. In terms of text structure, paragraphs are arranged to meet the reading habits of Western readers; the metaphor in the original work is retained during his translation. At the cultural level, literal translation, transliteration, and transliteration with notes are often adopted when translating Evenki folklore; in translating sacrifices, totem worship, and religious ceremonies, both the original language style and form are retained, faithful to the original. At the level of communication, the original intention is respected and the theme of the original text is reproduced based on the understanding of the original text and the purpose of communication is achieved at last.

A good translation will not only preserve the words specific to Evenki culture and the form by using figures of speech but convey of the main idea of the original fiction. Bruce Humes has been in China for over 30 years. His life experiences and interest have played a significant part in forming the ideas towards the ethnic groups, which exerts great influence on his choice of translation strategies. He successfully transmitted the theme of this remarkable work and provided a panorama about Evenki culture for western readers. Meanwhile, the harmonious coexistence and interdependence of human beings and nature the work indicate has become a global theme, which will provide some valuable implications for readers around the world.

\section{REFERENCES}

[1] Chi, Z. J. (2013). The Last Quarter of the Moon. Trans. Bruce Humes. Harvill Secker.

[2] Chi, Z. J. (2010). The Last Quarter of the Moon. People's Literature Publishing House.

[3] Hu, A. J. (2010). Translator Model, Translating Strategy, and the "Going Out" Project to Promote Chinese Literature Abroad: With American Sinologist Howard Goldblatt as an Exemplar, Chinese Translators Journal, 6, 10-16.

[4] Liu, J. J.(2012). Analysis of the Shaman Culture Embodied in The Last Quarter of the Moon, Jiannan Literature, 3, 61.

[5] Nord, C. (1997). Translating as a Purposeful Activity: Functionalist Approaches Explained. St Jerome.

[6] Nord, C. (2005). Text Analysis in Translation: Theory, Methodology and Didactic Application of a Model for Translation-Oriented Text Analysis. Rodopi.

Yuxuan He, MA Candidate in the Foreign Languages College, Inner Mongolia University, China. Her academic interest includes translation studies.

Jinyu Liu (Corresponding Author), Ph.D, Professor in the English Department of the Foreign Languages College, Inner Mongolia University, China. Her academic interest includes Inner Mongolian translation history, pedagogy and training, East Asian tran slation history.

Jianhua Wang, MA, Lecture in the Foreign Languages College, Inner Mongolia University, China. His academic interest includes translation studies, pedagogy and training. 